\title{
Aspectos morfológicos e morfométricos da traquéia em gansos domésticos
}

\author{
Tatiana Carlesso Santos ${ }^{1 *}$ \\ Hugo Andrés Gutiérrez Trujillo \\ Miryan Lança Vilia Alberto ${ }^{2}$ \\ Cheston Cesar Honorato Pereira ${ }^{3}$ \\ Carla Cristina Ferrari ${ }^{4}$ \\ Anita Menconi ${ }^{4}$ \\ Pedro Primo Bombonatto ${ }^{2}$ \\ ${ }^{1}$ Departamento de Zootecnia, Universidade Estadual de Maringá \\ Av. Colombo, 5790, Campus Universitário, CEP 87020-900, Maringá - PR, Brasil \\ ${ }^{2}$ Departamento de Cirurgia, Faculdade de Medicina Veterinária e Zootecnia da Universidade de São Paulo \\ Av. Prof. Dr. Orlando Marques de Paiva, 87, CEP 05508-000, São Paulo - SP, Brasil \\ ${ }^{3}$ Centro Regional Universitário de Espírito Santo do Pinhal \\ Caixa Postal 5, CEP 13990-000, Espírito Santo do Pinhal - SP, Brasil \\ ${ }^{4}$ Médica Veterinária autônoma \\ *Autor para correspondência \\ tcsantos@uem.br
}

\section{Resumo}

Estudou-se a morfologia da traquéia de gansos domésticos, caracterizando seus aspectos macroscópicos e morfométricos. Para tanto, foram utilizados 31 gansos domésticos adultos, machos e fêmeas, oriundos de criadouros comerciais, os quais foram eutanasiados por meio de inalação de clorofórmio, seguindo-se fixação em solução aquosa de formol a 10\%. A traquéia foi dissecada desde seu início, caudalmente à laringe, até sua bifurcação já na cavidade celomática. Os resultados mostraram que a traquéia dos gansos é composta por $144 \pm 12$ anéis cartilagíneos completos, e em média possui $33 \pm 2,7 \mathrm{~cm}$ de comprimento. A luz da traquéia apresenta-se ovalada, com um ligeiro achatamento dorso-ventral, tornando-se cilíndrica caudalmente a partir do seu terço médio. Os valores morfométricos obtidos para machos e fêmeas adultos não mostraram diferenças estatísticas significativas $(\mathrm{p}<0,05)$, sugerindo que não há dimorfismo sexual evidente para as características analisadas.

Unitermos: traquéia, gansos, sistema respiratório

\section{Abstract}

Morphologic and morphometric aspects of the domestic geese trachea. The tracheal morphology of 31 domestic geese was studied in order to characterize the morphometric and macroscopic aspects. Domestic geese, adult, male and female, from regular breeders, were utilized. The animals were euthanized by chloroform inhalation and fixed in 10\% formaldehyde in aqueous solution. The trachea was dissected, beginning caudal at 
the larynx, up to its bifurcation inside the coelomatic cavity. The results demonstrated that the goose trachea is formed by $144 \pm 12$ complete tracheal rings and that has a total length of $33 \pm 2.7 \mathrm{~cm}$ on average. The trachea lumen is ovulated, flattened dorso-ventrally, and cylindrical in the middle part. The morphometric data from goose tracheas in males and females did not differ statistically $(\mathrm{P}<0.05)$, suggesting that with regard to these characteristics there is no sexual dimorphism in this species.

Key words: trachea, goose, respiratory system

\section{Introdução}

A traquéia nas aves está composta por anéis cartilagíneos completos e compactos (Dyce et al., 1990), acompanha o esôfago no seu segmento cervical, e localiza-se ventralmente à coluna vertebral (McLelland, 1989). O primeiro anel traqueal está preso à extremidade caudal da cartilagem cricóide por meio de tecido conjuntivo colagenoso. $O$ curso da traquéia não segue o da coluna vertebral cervical, em sua extremidade cranial é mediana em posição, inclina-se à direita e encontra-se ventro-lateralmente às vértebras cervicais, permanecendo no antímero direito até que se aproxima da entrada torácica, local em que se torna novamente mediana (King e White, 1975).

De acordo com Portman (1950), a traquéia pode ser mais longa que o pescoço, o que promove curvas na entrada do tórax. Este fato ocorre em aves de pescoço longo. Em algumas espécies, prolonga-se consideravelmente e enovela-se na região esternal em uma fenda óssea do esterno, podendo mesmo ter as alças intraesternais da traquéia desenvolvidas em um grau extremo. Em aves aquáticas pode haver variações quanto a morfologia da traquéia, como é o caso dos pingüins, animais em que a traquéia após os primeiros dois centímetros, divide-se em dois tubos simples (Zeek, 1951).

Os anéis traqueais das aves são tipicamente completos e, em Gallus, o primeiro anel e os quatros últimos são simples, os demais possuem uma constrição ao meio, ocorrendo sobreposição entre eles (King e White, 1975). McLelland (1989) informa ainda que o número de anéis traqueais varia consideravelmente em função do comprimento do pescoço. Pequenos pássaros normalmente possuem de 30 a 40 anéis traqueais, enquanto um flamingo pode ter cerca de 350 . Entre as aves domésticas, os perus possuem de 120 a 150, os galos domésticos de 107 a 138 (Hogg, 1982), e os patos 120 anéis (Cover, 1953).
Os anéis traqueais conectam-se através do ligamento anular, e a traquéia termina por bifurcar-se. $\mathrm{Na}$ seqüência, observa-se a caixa de voz das aves, a siringe, semelhante a um complicado tímpano ou formação labiríntica (Koch, 1973). Nos penípedes, a traquéia tende a desviar-se para a direita, seu lume é circular e os últimos 12 anéis traqueais formam espaços intercartilaginosos. A siringe é formada pelos dois últimos anéis traqueais e pelos oito primeiros anéis bronquiais (Cover, 1953).

A literatura, entretanto, é escassa, no que se refere às descrições morfológicas, ao comportamento e aos aspectos morfométricos da traquéia. Isso motivou este estudo, uma vez que o ganso, ave da família Anhimidae, possui um papel econômico importante em pequenas propriedades, onde são criados animais sem raça definida, e que representam, muitas vezes, a principal fonte de renda familiar. Assim, o conhecimento da morfologia desses animais torna-se fundamental para subsidiar o incremento de sua produção e exploração zootécnica, uma vez que o sistema respiratório é, dos sistemas orgânicos, aquele mais frequentemente afetado nas aves, seja por doenças virais, bacterianas ou outras que acarretam, muitas vezes, perda de todo plantel muito rapidamente. $\mathrm{O}$ aproveitamento econômico, seja ele em larga escala ou em pequenas propriedades, deve ser embasado nos conhecimentos científicos para que se obtenha todo o potencial de rendimento da espécie. Desta forma, este trabalho visa descrever morfologicamente as estruturas que compõem a traquéia dos gansos domésticos, caracterizando seus aspectos macroscópicos e morfométricos, além de verificar a existência de dimorfismo sexual em relação aos parâmetros analisados.

\section{Material e Métodos}

Foram utilizados 31 gansos (Anser domestica), sendo 17 machos e 14 fêmeas, adultos, obtidos em criadouros comerciais, os quais foram encaminhados 
ao Laboratório do Centro Regional Universitário de Espírito Santo do Pinhal, onde foram eutanasiados por inalação de clorofórmio. As aves foram perfundidas com solução aquosa de formol a 10\% pela artéria isquiática, e mantidas em cubas com a mesma solução fixadora por no mínimo 48 horas.

Visando a identificação da morfologia traqueal e suas relações, as aves foram dissecadas na face ventral do pescoço e na entrada da cavidade celomática. O comprimento da traquéia foi tomado do primeiro ao último anel traqueal (sentido crânio-caudal), foi contado o número destes anéis e foram tomados os diâmetros correspondentes à altura (dorso-ventralmente) e largura (látero-lateralmente), em quatro diferentes pontos da extensão da traquéia: na região dos primeiros cinco anéis traqueais, no terço médio do pescoço, na base do pescoço (cranial a entrada da cavidade celomática), onde a traquéia apresenta-se mais larga, e cranialmente à siringe.

Os dados obtidos, em machos e fêmeas, foram analisados isoladamente pelos testes de $\mathrm{t}$ de Student $\mathrm{e}$ $F$ de Freedman $(p<0,05)$. Os dados foram analisados qualitativa e quantitativamente, quando então foram obtidos a média, o desvio-padrão e a amplitude. Realizou-se também teste de correlação de Pearson (r) entre os valores de comprimento e número de anéis traqueais.

Para a descrição macroscópica do órgão, foram realizadas análises radiográficas obtidas dos mesmos animais antes da eutanásia. Para descrição dos elementos estudados, foi utilizada a Nomina Anatomica Avium (Baumel, 1993).

\section{Resultados}

A traquéia dos gansos apresentou-se como um tubo que se estende ao longo do pescoço, desde a laringe até a siringe. Em seu terço inicial, possui disposição ventral à linha média da coluna vertebral e esôfago, assumindo posição lateral direita ao longo do pescoço. Na entrada da cavidade celomática torna-se ventral ao esôfago novamente. A flexão do pescoço não modificou a sintopia estabelecida entre a coluna vertebral e a traquéia, sendo que esta última permaneceu ventral à coluna vertebral, independente da angulação apresentada pelo pescoço (Figura 1).
Nos gansos estudados, a traquéia apresentou média geral de $33 \pm 2,76 \mathrm{~cm}$ de comprimento, sendo $33 \mathrm{~cm}$, em média, nos machos e $32 \mathrm{~cm}$ nas fêmeas, e valores máximo de 40 e mínimo de $28 \mathrm{~cm}$. A traquéia é constituída, em média, por $144 \pm 12$ anéis traqueais cartilagíneos completos, sendo que nos machos foram contados, em média, 148 anéis, e nas fêmeas, 142 anéis, com valores máximo de 168 e mínimo de 122 anéis.

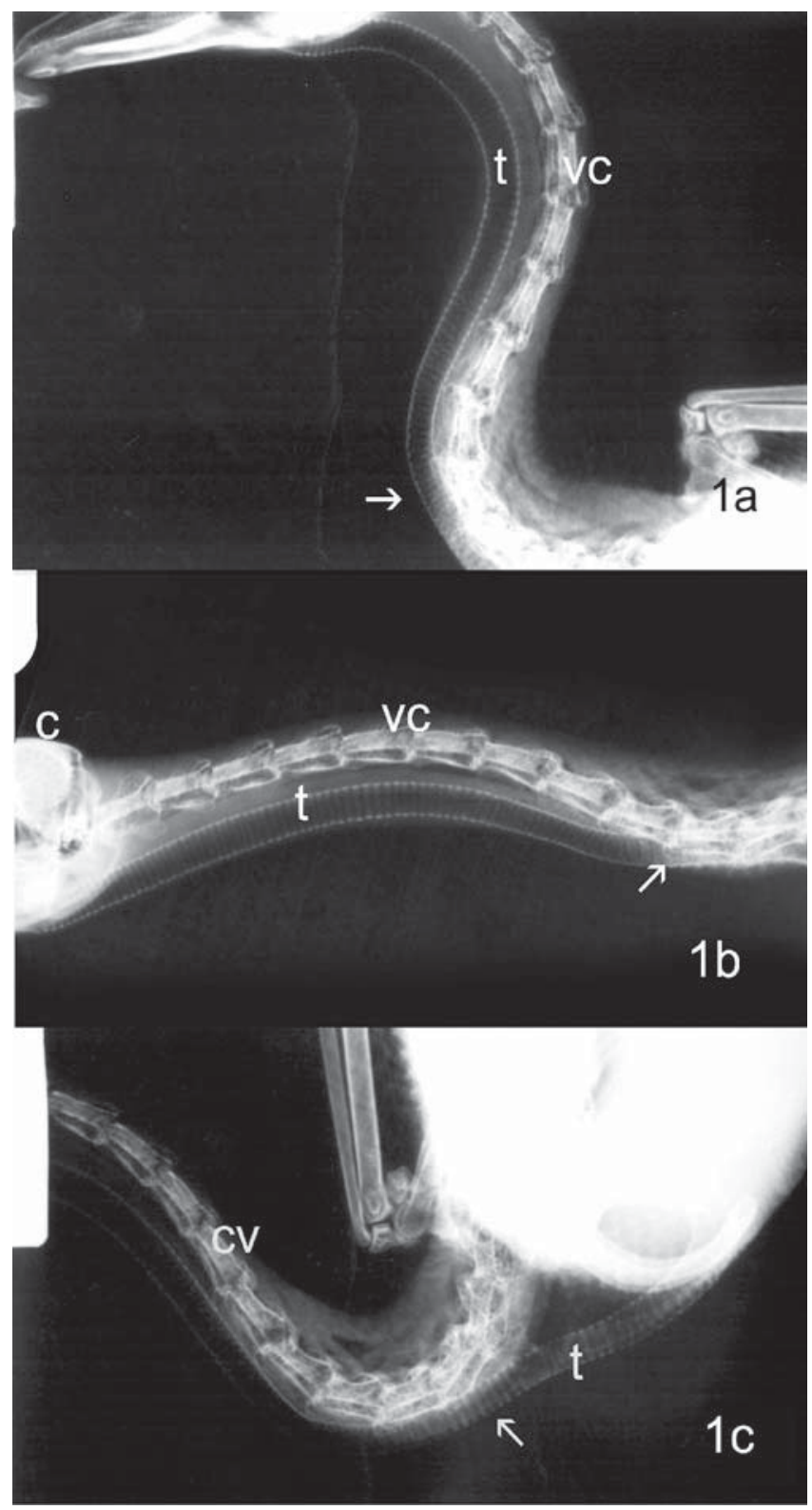

FIGURA 1: Imagens radiográficas em projeção látero-lateral, decúbito lateral direito, da região cervical de ganso adulto. Notar a posição da traquéia $(\mathrm{t})$ ventral às vértebras cervicais (vc) em estação forçada (1a), em hiper-extensão (1b) e em hiper-flexão (1c), em toda sua trajetória cervical, incluindo a entrada do tórax (seta). C - cabeça. 
A primeira cartilagem traqueal está disposta imediatamente caudal à cartilagem cricóide, e a última cartilagem é cranial à siringe. As cartilagens traqueais nos gansos apresentam-se como anéis completos com 1 a $2 \mathrm{~mm}$ de largura, possuindo um ligeiro estreitamento central, dividindo cada cartilagem em duas metades, direita e esquerda. Cada metade de uma cartilagem se sobrepõe a suas vizinhas, enquanto a metade restante esta sobreposta pelas metades das cartilagens cranial e caudalmente (Figura 2). Desta forma cada cartilagem possui uma metade visível e outra que esta sob suas vi- zinhas, determinando a característica de anéis traqueais intercalados.

Ao longo da traquéia, a forma da luz e as suas proporções variam. No segmento inicial (cinco primeiros anéis) a traquéia tende a ser arredondada e sua luz aumenta ligeiramente em sentido lateral, tornando-se mais ovalada no terço médio da traquéia. Na base do pescoço, a traquéia acentua o formato ligeiramente ovalado e aumenta sua luz consideravelmente. Na sua porção terminal, cranial à siringe, a traquéia retorna sue formato arredondado (Tabela 1 e Figura 3).

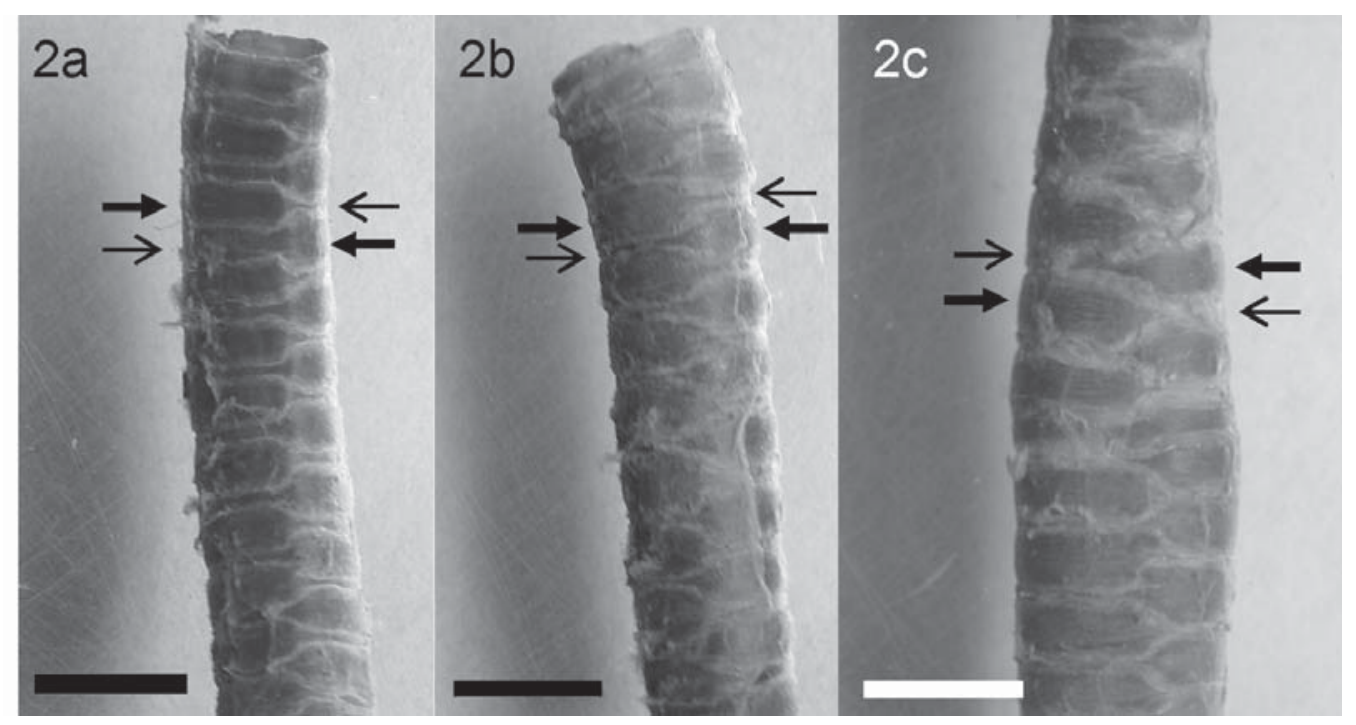

FIGURA 2: Traquéia em vista dorsal (a), ventral (b) e região da base do pescoço (c) de ganso doméstico adulto. Notar a disposição intercalada dos anéis traqueais que se sobrepõem aos anéis vizinhos em uma face (seta grossa) e se colocam sob a margem destes na outra (seta fina). Barra: 1 $\mathrm{cm}$.

TABELA 1: Valores médios e desvio-padrão para largura (larg.) e altura (alt.) (cm) em diferentes regiões da traquéia de gansos adultos.

\begin{tabular}{lcccccccc}
\hline \multirow{2}{*}{ Análise estatística } & \multicolumn{2}{c}{ Primeiros anéis } & \multicolumn{2}{c}{ Terço médio } & \multicolumn{2}{c}{ Base do pescoço } & \multicolumn{2}{c}{ Cranial à siringe } \\
\cline { 2 - 10 } & larg. & alt. & larg. & alt. & larg. & alt. & larg. & alt. \\
\hline Média & 1,10 & 0,83 & 0,94 & 0,81 & 1,40 & 1,11 & 0,85 & 0,74 \\
Desvio-padrão & 0,113 & 0,261 & 0,261 & 0,094 & 0,190 & 0,125 & 0,119 & 0,073 \\
Mínimo & 0,94 & 0,63 & 0,04 & 0,62 & 0,83 & 0,80 & 0,60 & 0,60 \\
Máximo & 1,35 & 1,09 & 1,15 & 0,98 & 1,76 & 1,35 & 1,14 & 0,88 \\
\hline
\end{tabular}




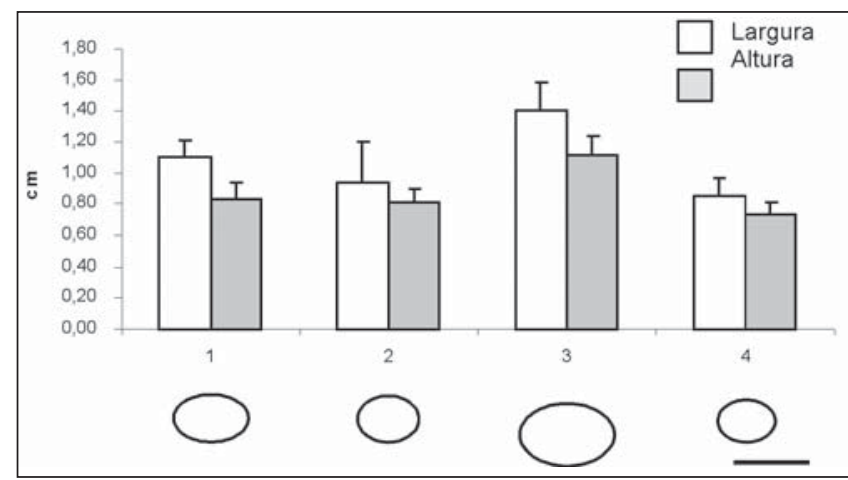

FIGURA 3: Valores médios e desvio-padrão para largura e altura $(\mathrm{cm})$ em diferentes regiões da traquéia de gansos adultos: primeiros anéis (1), terço médio (2), base do pescoço (3) e cranial à siringe (4). Abaixo, configuração esquemática da luz traqueal em cada região analisada. Barra: $1 \mathrm{~cm}$.

Em alguns exemplares do presente estudo, foram observadas áreas de fusão entre cartilagens traqueais, o que resultou na formação de placas de cartilagem com extensão variando de 0,5 a $3,5 \mathrm{~cm}$, sendo que nestes pontos a traquéia tornou-se inflexível.

O teste de correlação de Pearson entre o comprimento traqueal e o número de anéis traqueais em gansos adultos indicou que possivelmente o aumento no comprimento da traquéia é acompanhado pelo aumento em número de anéis, uma vez que estas variáveis possuem correlação positiva e de média para baixa intensidade $(\mathrm{r}=0,38)$.

Os teste estatísticos ( $\mathrm{t}$ e F) mostraram que não há diferenças significativas (95\%) entre os valores encontrados para machos e fêmeas, indicando a inexistência de dimorfismo sexual evidente para este órgão.

Com relação à musculatura da traquéia, o músculo traqueal acompanha o órgão ao longo de todo seu trajeto e, na sua porção caudal, observaram-se três pares de músculos: m. esternolaríngeo, m. traqueolaríngeo dorsal e m. traqueolaríngeo ventral. Estes músculos unem-se cranialmente à siringe para formar o músculo esternotraqueolaríngeo medial, enquanto o músculo esternotraqueolaríngeo lateral percorre a face lateral da traquéia, inserindo-se principalmente no osso hióide e na cartilagem cricóide, com uma pequena inserção na região cranial da traquéia.

\section{Discussão}

O sistema respiratório das aves difere em estrutura e função daquele encontrado nos mamíferos. Em função do ciclo de ventilação característico na respiração das aves, estas transferem mais oxigênio que os mamíferos em cada movimento respiratório (Gill, 1995). Neste sentido, a traquéia apresenta consideráveis diferenças em relação aos outros (Gill, 1995), pois nas aves os anéis são intercalados entre si, conferindo-lhe um alto nível de flexibilidade ao mesmo tempo em que permite variações de comprimento, uma vez que para se observar como os anéis traqueais realmente são, deve-se promover uma extensão do órgão (McLelland, 1989). No presente estudo, pôde-se observar que estas características são também comuns nos gansos.

A trajetória que a traquéia apresenta nos gansos vem confirmar os relatos de McLelland (1989) em aves em geral, onde localiza-se ventralmente na porção cranial da coluna vertebral, desviando-se completamente para a direita ou até mesmo assumindo posição dorsal à coluna vertebral quando o pescoço estiver flexionado. Particularmente no ganso, a posição da traquéia manteve-se ventral mesmo em flexão forçada.

A organização tridimensional dos anéis traqueais completos em gansos parece ser aquele encontrado nas aves em geral (King e White, 1975), havendo sobreposição de parte de cada anel com seus anéis vizinhos cranial e caudalmente. $\mathrm{O}$ formato da luz da traquéia dos gansos varia ao longo da extensão do órgão, semelhantemente ao descrito por Mennega (1964), que ainda complementa com informações sobre o pato branco de Pequin, no qual o arranjo dos anéis traqueais apresenta quatro entalhes, dois de cada lado, que se interconectam de forma que uma metade de cada anel fica externamente à traquéia e a outra fica internamente. No entanto, em relação aos quatro entalhes, tal característica não foi observada nos gansos domésticos, diferença esta que pode ser decorrente de variações entre famílias de aves.

Nos patos, a traquéia tende a se desviar para a direita, o lume é circular, os últimos 12 anéis traqueais formam espaços intercartilaginosos, e a siringe forma-se a partir dos dois últimos anéis traqueais e dos primeiros 8 anéis bronquiais (Cover, 1953). No seu 
término a traquéia bifurca-se e surge a caixa de voz das aves, a siringe, semelhante a um complicado tímpano ou formação labiríntica, à semelhança do descrito por Koch (1973).

Nos machos, o processo de vocalização é citado como sendo normalmente mais acentuado, entretanto, em gansos, não se observou dimorfismo sexual para os parâmetros analisados, o que de certa forma contradiz a versão proposta por Hogg (1982).

Estudos histológicos no Gallus demonstram que os anéis traqueais possuem um padrão de ossificação que se inicia nos anéis mais caudais e propaga-se em sentido cranial, sendo que de 20 a 30 anéis tornam-se completamente mineralizados (Hogg, 1982). No material do presente estudo, verificou-se a existência de anéis traqueais endurecidos com placas regionais delimitadas, sugerindo processo de ossificação da cartilagem e fusão entre elas.

Com relação à musculatura da traquéia, o mesmo padrão citado em galinhas domésticas (King e White, 1979; McLelland, 1965) foi observado nos gansos do presente estudo.

De acordo com as observações deste estudo, pôdese concluir que a disposição, a sintopia e o comportamento da traquéia dos gansos se assemelham àqueles de aves com pescoço longo. A traquéia possui 144 anéis traqueais cartilagíneos completos, sendo que a primeira cartilagem traqueal está imediatamente caudal à cartilagem cricóide, e a última está cranial à siringe. $\mathrm{O}$ formato do lume traqueal varia de oval a circular, não ocorrendo dimorfismo sexual evidente para os aspectos morfológicos e morfométricos analisados.

\section{Referências}

Baumel, J. J. 1993. Handbook of avian anatomy - Nomina anatomica avium $2^{\text {a }}$ ed. Nuttall Ornithological Club, Cambridge, Inglaterra, $779 \mathrm{pp}$.

Cover, M. S. 1953. Gross and microscopic anatomy of the respiratory system of the turkey. II The larynx, trachea, syrinx, bronchi and lungs. American Journal of Veterinary Research, 14: 230-238.

Dyce, K. M.; Sack, W. O., Wensing, C. J. G. 1990. Tratado de Anatomia Veterinária. Guanabara Koogan, Rio de Janeiro, Brasil, $663 p p$.

Gill, F. B. 1995. Ornithology. 2a ed. W. H. Freeman e Company, New York, USA, 766pp.

Hogg, D. A. 1982. Ossification of the laryngeal, tracheal and syringeal cartilages in the domestic fowls. Journal of Anatomy, 134: 57-71.

King, A. S.; White, S. S. 1975. Sistema respiratório das aves. In: Getty, R. (ed.) Sisson \& Grossman - Anatomia dos animais domésticos. $5^{\text {a }}$ ed., v.2. Guanabara Koogan, Rio de Janeiro, Brasil, p.1764-1797.

Koch, T. 1973. Anatomy of the chicken and domestic birds. Iowa University Press, Ames, USA, p.84-88.

Mennega, A. 1964. The tracheal rings in domestic birds. Poultry Science, 43 (1): 1279.

McLelland, J. 1965. The anatomy of the rings and muscles of the trachea of Gallus domesticus. Journal of Anatomy, 99 (3): 65156.

McLelland, J. 1989. Larynx and trachea. In: King, A. S. \& Mclelland, J. (eds). Form and Function in Birds. Academic Press, London, Inglaterra, p.69-103.

Portman, A. 1950. Les organes respiratoires. In: Grassè. Traité de Zoologie,

Anatomie, Systématique, Biologie. Tome XV, Masson, Paris, França, p.257-269.

Zeek, P. M. 1951. Double trachea in penguins and sea lions. The Anatomical Record, 111: 327-43. 